\title{
Improved reverse osmosis thin film composite biomimetic membranes by incorporation of polymersomes
}

Górecki, Radosaw Pawel; Reurink, Dennis Maik; Khan, Muntazim Munir; Sanahuja-Embuena, Victoria; Trzasku, Krzysztof; Hélix-Nielsen, Claus

Published in:

Journal of Membrane Science

Link to article, DOI:

10.1016/j.memsci.2019.117392

Publication date:

2020

Document Version

Peer reviewed version

Link back to DTU Orbit

Citation (APA):

Górecki, R. P., Reurink, D. M., Khan, M. M., Sanahuja-Embuena, V., Trzasku, K., \& Hélix-Nielsen, C. (2020). Improved reverse osmosis thin film composite biomimetic membranes by incorporation of polymersomes. Journal of Membrane Science, 593, [117392]. https://doi.org/10.1016/j.memsci.2019.117392

\section{General rights}

Copyright and moral rights for the publications made accessible in the public portal are retained by the authors and/or other copyright owners and it is a condition of accessing publications that users recognise and abide by the legal requirements associated with these rights.

- Users may download and print one copy of any publication from the public portal for the purpose of private study or research.

- You may not further distribute the material or use it for any profit-making activity or commercial gain

- You may freely distribute the URL identifying the publication in the public portal 
1 Improved reverse osmosis thin film composite biomimetic membranes by

2 incorporation of polymersomes

3

$4 \quad$ Radosław Górecki ${ }^{*}$, 2 , Dennis Maik Reurink ${ }^{3}$, Muntazim Munir Khan ${ }^{2}$, Victoria Sanahuja-

5 Embuena ${ }^{1,2}$, Krzysztof Trzaskuś ${ }^{2}$, Claus Hélix-Nielsen ${ }^{1}$

6

$7{ }^{1}$ Department of Environmental Engineering, Technical University of Denmark, Bygningstorvet 115, 2800 Kongens

8 Lyngby, Denmark

$9 \quad 2$ Aquaporin A/S, Nymøllevej 78, 2800 Kongens Lyngby, Denmark

$10{ }^{3}$ Membrane Science \& Technology, University of Twente, MESA+ Institute for Nanotechnology, P.O. Box 217, 7500

11 AE Enschede, The Netherlands

$12{ }^{*}$ Corresponding author, e-mail: rgor@env.dtu.dk ; rgo@aquaporin.com

13

14 Authors e-mail addresses:

15 Dennis Maik Reurink: d.m.reurink@utwente.nl; Muntazim Munir Khan: mmk@aquaporin.com;

16 Victoria Sanahuja-Embuena: visc@env.dtu.dk; Krzysztof Trzaskuś: ktr@aquaporin.com;

17 Claus Hélix-Nielsen: clhe@env.dtu.dk

18 
20 Biomimetic aquaporin-based membranes offer great promise as a disruptive water treatment

21 technology, due to their potential of improving membrane permeability without compromising solute 22 rejection. However, fabrication upscaling is challenging and therefore the technological potential of 23 biomimetic membranes remains unused. We propose an easily upscalable process based on bulk 24 hydration of diblock and triblock copolymer mixture for preparation of polymersomes which can 25 reconstitute aquaporin proteins. Such polymersomes are incorporated into biomimetic membranes 26 via polyamide active layer synthesis based on interfacial polymerization. By incorporation of blank 27 polymersomes, it was possible to improve water permeability of the membrane by $30 \%$, and by 28 incorporation of aquaporin reconstituting polymersomes by $50 \%$, compared to the membranes 29 without polymersomes. In both cases $\mathrm{NaCl}$ rejection was not affected. X-ray photoelectron 30 spectroscopy measurements confirmed incorporation of copolymers prepared with aquaporins into 31 the active polyamide layer without affecting the thickness of the membrane's active layer and surface 32 zeta-potential.

33

34 Keywords: Aquaporin; Biomimetic Membrane; Block Copolymers; Polymersomes; Interfacial 35 Polymerization. 
Ensuring access to water and sanitation for all is goal number 6 of the United Nation Sustainability

39 Goals [1]. Not only the demand for water is increasing across all sectors [2], the problems with water quality are growing on a global scale, even in regions considered as water-rich. In both developing and industrialized nations more contaminants, including trace organics such as pharmaceuticals and pesticides to heavy metals, are entering the water due to human activities $[3,4]$, which drives the development of more efficient water purification technologies [4] [5].

As a result of a high energy efficiency and manufacturing scalability combined with a small footprint [4,6], membrane technology becomes leading technology for high quality water purification [7]. For example, polyamide based reverse osmosis (RO) membranes are used worldwide for processes such as desalination [4], water reuse [8] and domestic tap water purification [9]. These membranes are mainly thin film composite (TFC) membranes with a thin (100-200 nm) polyamide (PA) active layer (AL) coated on a porous substrate which is supported by a non-woven fabric [10]. The broad application of TFC membranes has been accompanied by continuous performance improvements resulting in enhanced water permeability, high solute rejection, low energy demand and low fouling52 ability [11]. Recently, biomimetic approaches have attracted considerable interest [12]. Here, the membrane AL is doped with transmembrane proteins facilitating water transport exemplified by the use of the bacterial aquaporin protein isoform Aquaporin Z (AqpZ) [12,13]. However, industrial scale production and incorporation of aquaporins into the AL is not a trivial task due to the need for 57 elaborate protein purification and stabilization steps [14].

58 A common approach for AqpZ membrane incorporation is based on reconstitution into amphiphilic liposomes or polymersomes preserving the ternary and quaternary structure of the AqpZ and thus 
61 RO, forward osmosis (FO) and nanofiltration (NF) biomimetic membranes [10]. Polymersomes appear advantageous over liposomes for industrial applications due to their superior physical and chemical stability [16] as well as the possibility of introducing active groups for covalent bonding to the membrane AL [17]. However, the protein activity is generally reported to be lower in polymersomes compared to liposomes, presumably due to the increased hydrophobic mismatch between the hydrophobic polymer core layer thickness and transmembrane protein length [18]. In order to achieve efficient functional reconstitution of AqpZ proteins into polymersomes, the polymer matrix must resemble natural phospholipid membranes while preserving the advantages in stability. For example, AqpZ can be successfully reconstituted in triblock copolymers containing polydimethylsiloxane (PDMS) [19-22]. The conformational flexibility of the PDMS blocks allows insertion of membrane proteins where the polymer chains can adapt to the fixed dimensions of the proteins [18] and protein insertion can be further increased by addition of detergents [23]. Still, reconstitution of AqpZ with triblock copolymers containing less flexible polymer chains is possible and was reported for systems such as block-poly(isobutylene)-block-poly(ethyleneglycol)-blockpoly(isobutylene) (PIB-PEG-PIB) [24] or block-poly(ethyleneglycol)-block-poly(propyleneglycol)block-poly(ethyleneglycol) (PEG-PPG-PEG) [25].

The use of AqpZ liposomes (AQP-liposomes) has been reported for the manufacturing of TFC RO membranes, TFC nanofiltration (NF) membranes, and FO membranes [26] [27] [28]. AQP-liposome TFC RO membranes showed improvements in water permeability of up to $40 \%$ when compared to commercial membranes [26] and FO membranes with AQP-liposomes, achieved a water flux of 49.1 $\mathrm{Lm}^{-2} \mathrm{~h}^{-1}$ coupled with specific reverse salt flux of $0.10 \mathrm{gL}^{-1}$ (with $1 \mathrm{M} \mathrm{NaCl}$ as draw solution and deionised (DI) water as feed) [28]. However, natural lipids are prone to oxidation which has inspired the use of amphiphilic block copolymers, as they have a higher chemical and physical stability $[16,21,29]$. Moreover, the use of amphiphilic block copolymers allows for the introduction of active 
groups to the AQP-polymersomes that can participate in interfacial polymerization (IP) and thus be covalently bonded to the PA layer [20,21,30,31].

AqpZ-embedded polymersomes (AQP-polymersomes) made by amphiphilic block copolymers have been used in TFC membranes made via IP for FO [32]. However, for the applications in which transport through the TFC membrane is driven by a hydraulic transmembrane pressure gradient, the incorporation of AQP-polymersomes has not been reported yet. Moreover, the use of membranes with AQP-polymersomes has been limited to NF membranes with limited selectivity towards monovalent ions [30,31,33,34]. Another limitation for biomimetic membranes arises from challenges in manufacturing process scalability. The preparation of AQP-polymersomes reported in the literature has been limited to film rehydration techniques [19,21,22,30,31]. The major drawback of this technique stems from the high cost due to several processing steps and product losses [35,36].

Here we propose a novel, fully scalable method to prepare and introduce AQP-polymersomes into the AL of RO membranes. First, AqpZ proteins are functionally reconstituted into AQPpolymersomes, using an industrially scalable process based on bulk hydration and self-assembly of poly-2-methyl-2-oxazoline-block-poly(dimethylsiloxane) (PMOXA-PDMS) and poly(2-methyl-2oxazoline)-block-poly(dimethylsiloxane)-block-poly(2-methyl-2-oxazoline)

(PMOXA-PDMSPMOXA) copolymers with the addition of amine terminated poly(dimethylsiloxane) (A-PDMS). Secondly, AQP-polymersomes are successfully embedded into the membrane AL using the IP reaction between m-phenylenediamine (MPD) and trimesoyl chloride (TMC). This results in membranes with improved water permeability that maintain a high $\mathrm{NaCl}$ rejection. 


\section{Experimental}

\subsection{Preparation of polymersomes}

Polymersomes were prepared by the self-assembly method in an aqueous solution of phosphate buffered saline (PBS). PBS (pH 7.2, $136 \mathrm{mM} \mathrm{NaCl,} 2.6 \mathrm{mM} \mathrm{KCl)} \mathrm{was} \mathrm{prepared} \mathrm{by} \mathrm{dissolving} 8 \mathrm{~g}$ $\mathrm{NaCl}, 0.2 \mathrm{~g} \mathrm{KCl}, 1.44 \mathrm{~g} \mathrm{Na}_{2} \mathrm{HPO}_{4}$ and $0.24 \mathrm{~g}$ of $\mathrm{KH}_{2} \mathrm{PO}_{4}$ in $800 \mathrm{~mL}$ Milli Q purified $\mathrm{H}_{2} \mathrm{O}$, adjusting the $\mathrm{pH}$ to 7.2 with $\mathrm{HCl}$ and bringing the volume to $1 \mathrm{~L}$ with Milli $\mathrm{Q} \mathrm{H}_{2} \mathrm{O}$ [37]. All chemicals were analytical grade (Sigma Aldrich, Denmark). Polymersomes incorporating AqpZ (AQP-1) were prepared from a mixture of AqpZ protein and diblock PMOXA-PDMS and triblock PMOXA-PDMSPMOXA amphiphilic copolymer, according to the procedure described in the patent of Spulber and Gerstandt [37] . Briefly, $112 \mathrm{mg}$ of mixture of diblock PMOXA-PDMS and triblock amphiphilic copolymer PMOXA-PDMS-PMOXA (Aquaporin A/S, Denmark) and $100 \mu \mathrm{L}$ of aminopropyl terminated polydimethylsiloxane (A-PDMS) (Aquaporin A/S, Denmark) were mixed with $100 \mu \mathrm{L}$ of AqpZ-stock solution (5 mg/mL) (Aquaporin A/S, Denmark) and subsequently dissolved in 100 mL PBS with 0.05 \% Lauryldimethylamine $N$-oxide (LDAO) (Carbosynth Ltd., United Kingdom) and $0.5 \%$ solubilizer Kolliphor ${ }^{\circledR}$ HS 15 (KHS) (Sigma-Aldrich Denmark A/S, Denmark). The resulting solution was then stirred at 170 rpm for 10 hours at room temperature. Subsequently, the solution was firstly filtered through $0.5 \mu \mathrm{m}$ polyethersulfone (PES) filter and secondly through 0.22 $\mu \mathrm{m}$ PES filter (Sarstedt, Germany). The polymersomes without AqpZ (AQP-0) were prepared in exactly the same procedure, without adding AqpZ-stock to the solution.

2.2. Characterization of polymersomes and functional reconstitution of Aquaporin Z proteins

Size distribution of polymersomes was characterized by Nanoparticle Tracking Analyzer (NTA) Nanosight 3.1 Build 3.1.46 (Malvern Panalytical Ltd, UK), equipped with a charge-coupled device 
(CCD) camera. The camera level was set to 14 , slider shutter to 1485 , slider gain to 470 , and the recording was done with 30 FPS and 3600 number of frames. The samples were diluted 400 times with PBS buffer, resulting in concentrations of 41 (for AQP-0) and 56 (for AQP-1) particles per frame. The measurements were done at $23^{\circ} \mathrm{C}$. Zeta potential of the polymersomes solution has been measured with use of folded capillary cells DTS1070 on a Zeta Sizer Nano (Malvern Panalytical Ltd, UK). The functional reconstitution of AqpZ in polymersomes was analysed with the use of a StoppedFlow Spectrometer SX20 device (Applied Biophysics Inc, USA), equipped with a150 W xenon-arc lamp (Osram, Germany), using a monochromator set to a wavelength of $465 \mathrm{~nm}$. For each SF measurement, $10 \mu \mathrm{L}$ of polymersome solution and $10 \mu \mathrm{L}$ of $0.5 \mathrm{M} \mathrm{NaCl}$ solution were rapidly mixed in a $20 \mu \mathrm{L}$ optical cell at $25^{\circ} \mathrm{C}$. When polymersomes are exposed to the $\mathrm{NaCl}$ solution, the osmotic pressure difference causes water efflux from the polymersomes, resulting in a decrease in volume,thereby causinga change in the refractive index of the solution [38]. The kinetics of these changes are measured by the light scattering detector. The higher the water efflux through the polymersome membrane observed - the more rapid volume change occurs. The kinetics of this process are obtained from the Stopped-Flow Light Scattering (SFLS) measurements by fitting the average of five readings to double exponential equation $1[19,21,39,40]$ with use of OriginPro software (OriginLab Corporation, USA):

$$
Y=\sum_{i=1}^{N} c_{i} e^{-k_{i} t}
$$

where $Y$ is light scattering intensity, $N$ is the number of exponential terms $(N=2), t$ is time (s), $c_{i}$ is relative amplitude and $k_{i}$ are the exponential coefficients $\left(\mathrm{s}^{-1}\right)(\mathrm{i}=1,2)$.

152 Faster exponential coefficient $k_{2}\left(\mathrm{~s}^{-1}\right)$ is attributed to the water efflux from the polymersomes [21]. 153 The osmotic water permeability through polymersomes is calculated with equation 2 [21,39-41]: 


$$
P_{f}=\frac{k_{2}}{S_{A} / V_{0}} V_{w} \Delta_{o s m}
$$

where $P_{f}$ is osmotic water permeability $\left(\mu \mathrm{m} \cdot \mathrm{s}^{-1}\right), k_{2}$ is the faster exponential coefficient $\left(\mathrm{s}^{-1}\right), S_{A}$ is

vesicle surface area $\left(\mu \mathrm{m}^{2}\right), V_{0}$ is initial vesicle volume $\left(\mu \mathrm{m}^{3}\right), V_{w}$ is molar volume of water $(0.018$

$\mathrm{L} \cdot \mathrm{mol}^{-1}$ ), and $\Delta_{o s m}$ is the osmolarity difference that drives the vesicle volume change (osmol $\left.\cdot \mathrm{L}^{-1}\right)$.

\subsection{Preparation of membrane TFC AL}

MPD ( $\geq 99 \%$ for synthesis), $\varepsilon$-Caprolactam ( $\geq 99 \%$ for synthesis) and TMC ( $\geq 99 \%$ for synthesis) were obtained from Merck KGaA (Germany) and used as received. Isopar ${ }^{\mathrm{TM}} \mathrm{E}$ was obtained from

Brenntag Nordic A/S (Denmark) and filtered through a mechanical filter (approximately $500 \mu \mathrm{m}$ )

prior to use. Anhydrous citric acid was obtained from Citrique Belge (Belgium) and used as received.

A polysulfone (PSF) ultrafiltration membrane was obtained from Aquaporin A/S (Denmark) and used

as the support membrane. The support membrane was stored in DI water overnight prior to AL fabrication.

The PA AL layer was synthesized by an in-situ IP reaction between MPD monomer in the aqueous phase and TMC monomer in organic solvent. The PES support membrane was cut into $270 \times 170 \mathrm{~mm}$ pieces and clipped to stainless-steel frames on the edges. This membrane frame was immersed in a

172 solution containing $3 \mathrm{wt} \%$ of MPD and $3 \mathrm{wt} \%$ of $\varepsilon$-Caprolactam. The solution also contained $3 \mathrm{wt} \%$ of AQP-1 or $3 \mathrm{wt} \%$ AQP-0 when polymersomes were loaded to the membrane. The immersion in

174 aqueous solution was 30 seconds. The excess solution was removed from the surface of the membrane 175 by air gun. Subsequently $50 \mathrm{~mL}$ of $0.09 \mathrm{wt} \%$ TMC organic solution (in Isopar ${ }^{\mathrm{TM}} \mathrm{E}$ ) was applied to 176 the surface of the horizontally placed membrane frame. After 30 seconds, the excess of organic 
solution was poured out and the surface of the membrane was dried with an air gun. The membrane was then immersed for 4 minutes in the $20 \mathrm{wt} \%$ citric acid bath preheated to $70^{\circ} \mathrm{C}$ to remove the unreacted amine monomers [42]. Afterwards, the membrane was immersed in the DI water at $70^{\circ} \mathrm{C}$ for 2 minutes. Finally, the membranes were flushed with DI water, removed from the stainless-steel frames and stored in the DI water overnight prior to testing.

\subsection{Membrane characterization}

\subsubsection{Scanning electron microscopy}

Cross-sections and surface micrographs of the polyamide layer were taken using a field emission scanning electron microscope (JSM-7610F, JEOL, Japan). All samples were sputter coated (Quorum Q150T ES, United Kingdom) with a $5 \mathrm{~nm}$ thick layer of chromium. Cross sections were prepared by breaking the membrane samples in liquid nitrogen with a razor blade. All samples were vacuum dried prior to sputter coating and images were taken at an accelerating voltage of $1.0 \mathrm{kV}$.

\subsubsection{X-ray photoelectron spectroscopy}

The X-ray photoelectron spectroscopy (XPS) measurements were done with use of Scanning XPS microprobe Quantera SXM (Physical Electronics, USA). The base pressure was $<6.6 \times 10^{-8} \mathrm{~Pa}$, the power of monochromatic $\mathrm{Al} \mathrm{K \alpha}(\mathrm{h} v=1486.6 \mathrm{eV})$ was $25 \mathrm{~W}$ and the current was $2.6 \mathrm{~mA}$. The used beam size was $100 \mu \mathrm{m}$. A lower energy electron flood gun was used to supply the missing photoelectrons and Auger electrons. Low energy argon ions were used to remove the surplus of 


\subsubsection{Zeta $(\zeta)$ potential measurements}

200 Zeta potential of the flat sheet membranes was measured using streaming potential measurements 201 with an electrokinetic analyzer (SurPass, Anton Paar, Graz Austria). Two samples were affixed to 10 202 x 20 mm sample holders with double-sided tape using an adjustable gap cell. Inside the adjustable 203 gap cell a rectangular silicone block ensures the the chamber is sealed. The two sample holders were 204 placed opposite each other in the adjustable gap cell creating a rectangular slit between the two 205 membrane samples. The slit, or gap height, was adjusted to $110 \mu \mathrm{m}$. A $5 \mathrm{mM} \mathrm{KCl}$ solution was 206 allowed to flow through the adjustable gap cell under ambient conditions. Under a given pressure 207 difference, the flow through the cell creates a streaming current. With the measured streaming current 208 (A), dI, and the applied pressure difference $(\mathrm{Pa}) \mathrm{dp}$, the zeta potential $(\mathrm{V}) \zeta$, can be calculated 209 according to equation 3:

$$
\zeta=\frac{\mathrm{dI}}{\mathrm{dp}} \cdot \frac{\eta}{\varepsilon \cdot \varepsilon_{0}} \cdot \frac{L}{A}
$$

where, $\eta$ is the dynamic viscosity $(\mathrm{Pa} \cdot \mathrm{s})$ of the electrolyte, $\varepsilon$ the dielectric constant $(-)$ of the 214 electrolyte, $\varepsilon_{0}$ the permittivity of vacuum $\left(\mathrm{F} \cdot \mathrm{m}^{-1}\right)$, $\mathrm{L}$ is the length $(\mathrm{m})$ of the streaming channel, and 215 A is the cross-section area $\left(\mathrm{m}^{2}\right)$ of the streaming channel. Every membrane sample was measured a minimum of six times in the $5 \mathrm{mM} \mathrm{KCl}$ solution and for every measurement point three membrane 217 samples were measured. From this data a standard deviation was derived.

\subsection{Membrane performance evaluation}

The performance of the prepared TFC membranes wasevaluated with a reverse osmosis testing setup 
prepared membrane was cut into 3 coupons of $58 \mathrm{~mm}$ x $112 \mathrm{~mm}$ to fit the CF042P Sterlitech cells.

223 The solution of $500 \mathrm{ppm} \mathrm{NaCl}$ (Akzo Nobel Salt A/S, Denmark) was used as a feed and has been 224 circulated through the cells on the side facing the AL of the membrane. The testing pressure applied 225 was 5 bar. The feed solution at $25^{\circ} \mathrm{C}$ was introduced into the filtration cell with a flow-rate 226 of $60 \mathrm{Lh}^{-1}$, which corresponds to the cross-flow velocity of $20 \mathrm{~cm} / \mathrm{s}$. Before permeate sample 227 collection, membrane samples were compressed for 30 minutes. Permeate samples were collected 228 and weighted to obtain liquid permeability $\left(L_{p}\right)$ according to equation 4 :

$$
L_{p}=\frac{\Delta V}{\Delta t \cdot A \cdot(\Delta P-\Delta \pi)}
$$

232 where, $L_{p}$ is the water permeability of the membrane $\left(\mathrm{L} \cdot \mathrm{m}^{-2} \cdot \mathrm{h}^{-1} \cdot \mathrm{bar}^{-1}\right), \Delta V$ is the volume of the 233 collected permeate sample (L), $\Delta t$ is the sampling time (s), $A$ is the active area of the membrane $\left(\mathrm{m}^{2}\right)$, $234 \Delta P$ is the applied pressure (bar), and $\Delta \pi$ is the osmotic pressure of the feed solution (bar).

235 Conductivity of the obtained samples was measured by Ultrameter II 6PFCE (Myron L ${ }^{\circledR}$ Company, 236 USA) and was applied for calculation of $\mathrm{NaCl}$ concentration in feed and permeate samples, which 237 was later used to calculate $\mathrm{NaCl}$ rejection according to equation 5:

$$
R(\%)=\left(1-\frac{C_{p}}{C_{f}}\right) \times 100 \%
$$

241 where, $R$ is the membrane salt rejection, $C_{p}$ is the concentration of $\mathrm{NaCl}$ in the permeate, and $C_{f}$ is 242 the concentration of the $\mathrm{NaCl}$ in the feed solution. 


\subsection{Functional reconstitution of Aquaporin $\mathrm{Z}$ into polymersomes}

246 The characteristics of polymersomes are summarized in Table 1.

Table 1. Size distribution, $\zeta$-potential, $\mathrm{pH}$ and osmotic water permeability of PMOXA-PDMS-PMOXA polymersomes. D10, D50 and D90 are particle size distribution intercepts of $10 \%, 50 \%$ and $90 \%, \pm$ values indicate standard error.

\begin{tabular}{|c|c|c|c|c|c|c|c|c|}
\hline $\begin{array}{c}\text { Type of } \\
\text { polymersomes }\end{array}$ & $\begin{array}{l}\text { Mean } \\
\text { size } \\
(\mathbf{n m})\end{array}$ & $\begin{array}{l}\text { D10 } \\
(\mathbf{n m})\end{array}$ & $\begin{array}{l}\text { D50 } \\
\text { (nm) }\end{array}$ & $\begin{array}{l}\text { D90 } \\
(\mathrm{nm})\end{array}$ & $\begin{array}{c}\text { Conc. of } \\
\text { polymersomes } \\
\left(\text { particles` } \mathbf{m L}^{-1}\right)\end{array}$ & $\begin{array}{c}\zeta- \\
\text { potential } \\
(\mathrm{mV})\end{array}$ & $\mathbf{p H}$ & $\begin{array}{c}\text { Osmotic } \\
\text { water } \\
\text { permeability } \\
\text { P }_{\mathrm{f}}\left(\mu \mathrm{m} \cdot \mathrm{s}^{-1}\right)\end{array}$ \\
\hline AQP-1 & $154 \pm 1$ & $\begin{array}{r}99 \\
\pm 1\end{array}$ & $\begin{array}{l}126 \\
\pm 2\end{array}$ & $\begin{array}{l}234 \\
\pm 3\end{array}$ & $\begin{array}{c}3.26 \times 10^{11} \\
\pm 7.08 \times 10^{9}\end{array}$ & +0.9 & 8.03 & $143 \pm 5$ \\
\hline AQP-0 & $153 \pm 3$ & $\begin{array}{l}102 \\
\pm 1\end{array}$ & $\begin{array}{l}134 \\
\pm 1\end{array}$ & $\begin{array}{l}208 \\
\pm 8\end{array}$ & $\begin{array}{c}4.44 \times 10^{11} \\
\pm 1.24 \times 10^{10}\end{array}$ & +0.4 & 8.10 & $109 \pm 3$ \\
\hline
\end{tabular}

The measurements obtained by NTA show that AQP-1 and AQP-0 have very comparable mean sizes and size distribution, namely $154 \pm 1 \mathrm{~nm}$ for AQP-1 and $153 \pm 3 \mathrm{~nm}$ for AQP-0. In both solutions concentration of polymersomes was comparable as well, $3.26 \times 10^{11} \pm 7.08 \times 10^{9} \mathrm{~nm}$ for AQP-1 and $4.44 \times 10^{11} \pm 1.24 \times 10^{10} \mathrm{~nm}$ for AQP-0, respectively. This indicates that the presence of AqpZ in the solution does not affect the self-assembly process, and that the formation of polymersomes does not influence the average size nor the concentration of polymersomes. The $\zeta$-potential of both AQP-1 and AQP-0 was similar, $+0.9 \mathrm{mV}$ and $+0.4 \mathrm{mV}$ respectively, confirming no difference in surface charge between AQP-1 and AQP-0 polymersomes. Measured $\zeta$-potential suggest that the electrostatic repulsion between polymersomes are negligible. It is suspected that the stability of the solution is maintained by steric stabilization induced by the presence of copolymers and surfactants [43]. The 260 faster exponential coefficient obtained from the SFLS experiment (see Figure 1) was larger for AQP$2611\left(\mathrm{k}_{2}=54 \pm 2 \mathrm{~s}^{-1}\right)$ than for AQP-0 $\left(\mathrm{k}_{2}=41 \pm 1 \mathrm{~s}^{-1}\right)$. As a result, osmotic water permeability calculated 262 from the faster exponential coefficient $\left(\mathrm{k}_{2}\right)$ was about $32 \%$ larger for AQP-1 polymersomes than for 263 AQP-0 polymersomes $-143 \pm 5 \mu \mathrm{m} \cdot \mathrm{s}^{-1}$ and $109 \pm 3 \mu \mathrm{m} \cdot \mathrm{s}^{-1}$, respectively (Table 1). 


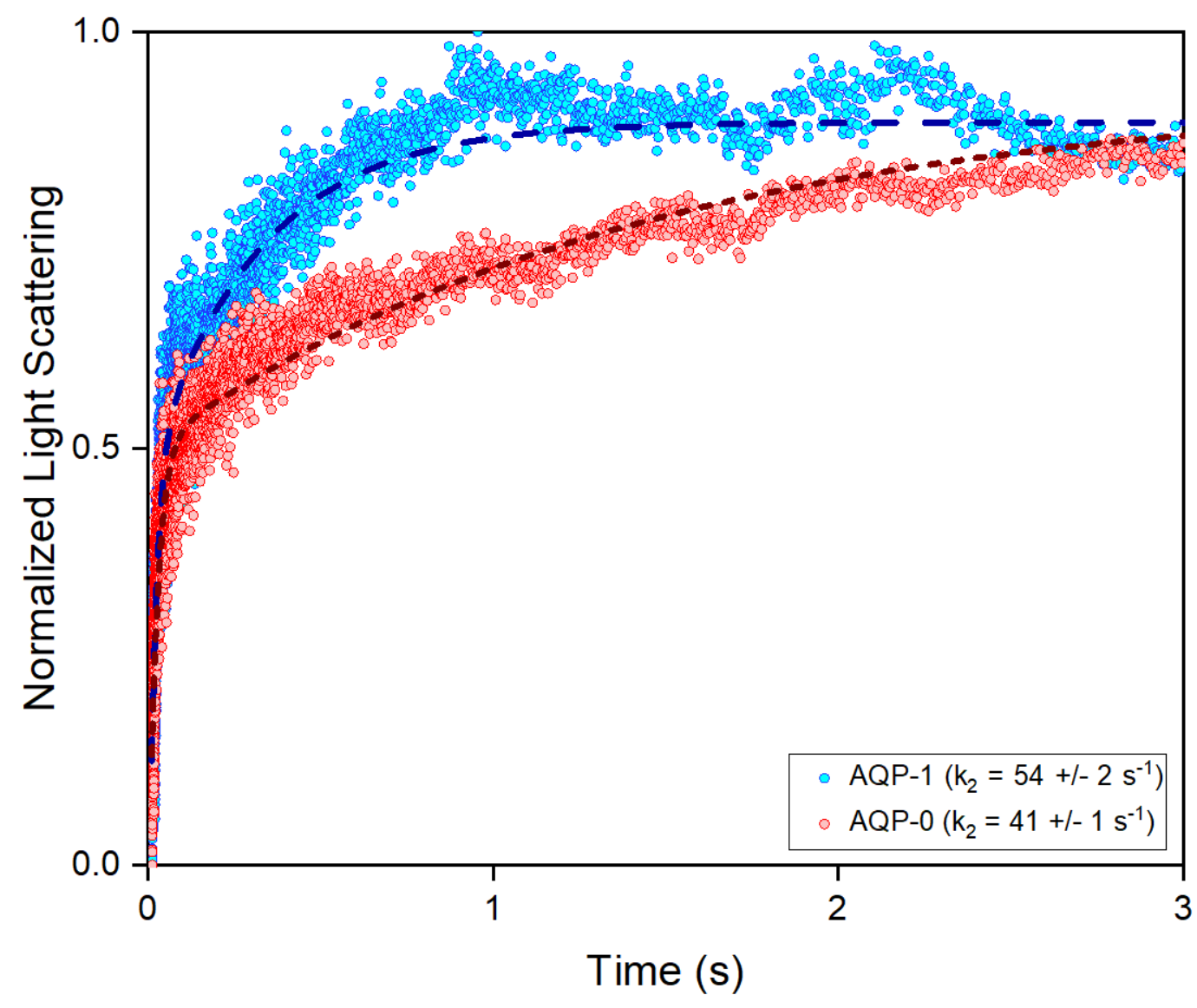

265 Figure 1. Stopped-flow light scattering readings for AQP-0 and AQP-1 polymersomes - measured against $0.5 \mathrm{M} \mathrm{NaCl}$ at $25^{\circ} \mathrm{C}$. The data points presented here are average values from 5 separate measurements for each sample, while dashed 267 lines represent the fits made with double exponential equation 1.

268 The increased permeability of AQP-1 compared to AQP-0 indicates a successful functional 269 reconstitution of AqpZ into amphiphilic membrane of polymersomes, without influencing other 270 characteristics of polymersomes such as hydrodynamic diameter and zeta potential. In this case, the 271 observed difference in water permeability between AQP-0 and AQP-1 is significantly lower than 272 usually reported in the literature for PMOXA-PDMS-PMOXA polymersomes containing aquaporins. 273 In multiple articles, authors have reported greater increases in permeabilities of the polymersomes 274 made of PMOXA-PDMS-PMOXA amphiphilic block copolymers. In the early work on AqpZ 
275 reconstituting polymersomes, Kumar et al. reported permeabilities of $0.8 \mu \mathrm{ms}^{-1}$ for blank 276 polymersomes that increased to $74 \mu \mathrm{ms}^{-1}, 1500 \mu \mathrm{ms}^{-1}$ and $2500 \mu \mathrm{ms}^{-1}$ with increased AqpZ loading 277 in the $\mathrm{PMOXA}_{15}-\mathrm{PDMS}_{110}-\mathrm{PMOXA}_{15}$ measured at 5.5 ${ }^{\circ} \mathrm{C}$ [19]. In a paper from 2012, Zhong et al. 278 reported an increased permeability from $0 \mu \mathrm{ms}^{-1}$ for PMOXA $_{10}-\mathrm{PDMS}_{70}-\mathrm{PMOXA}_{10}$ blank to 1673 $279 \mu \mathrm{ms}^{-1}, 2049 \mu \mathrm{ms}^{-1}$ and $2350 \mu \mathrm{ms}^{-1}$, however, the temperatures at which the measurements were done 280 are not specified [31]. In another article by Duong and co-workers, no flux is reported for the control 281 disulphide functionalized $\mathrm{PMOXA}_{10}-\mathrm{PDMS}_{75}-\mathrm{PMOXA}_{20}$ polymersomes, whereas the flux increase 282 to 2595 and $4680 \mu \mathrm{ms}^{-1}$ when AqpZ are incorporated (measured at $25^{\circ} \mathrm{C}$ ) [30]. Grzelakowski et al., 283 using amine functionalized PMOXA-PDMS-PMOXA reports fluxes of $184 \mu \mathrm{ms}^{-1}$ for control and $2844788 \mu \mathrm{ms}^{-1}$ for AqpZ-loaded polymersomes, however, no block lengths are specified, and neither 285 were the temperatures at which the permeabilities were measured [21].

286 Here, a relatively low increase in permeability of the polymersomes after reconstitution of the AqpZ 287 and high permeability of the blank polymersomes implies that an amphiphilic membrane of prepeared 288 polymersomes is already highly permeable to water. It differs from the previously reported 289 approaches, in which polymersomes show no transport or very limited transport of water through 290 amphiphilic membranes. We speculate that the reason behind increased permeability of blank 291 polymersomes is the effect of the surfactants on the amphiphilic copolymer wall of the vesicles. The 292 surfactant molecules are known to incorporate into the outer leaflet of the polymeric bilayer causing 293 its partial solubilisation [44]. This will cause an enhanced permeability and as the concentration of 294 the surfactant increase, may also lead to disintegration of polymersomes [45]. However, this is not 295 the case in this study, as the size measurement does not imply the presence of a significant population 296 of structures below $100 \mathrm{~nm}$ (Table 1). 
298 Biomimetic TFC RO membranes were prepared according to the protocol described in section 2.2. 299 The TFC layer was doped with AQP-0 and AQP-1 polymersomes in order to investigate the effect of 300 aquaporin proteins on the performance and properties of the RO membranes. Membranes without 301 polymerosomes were also prepared as a control of the experiment.

302

\subsubsection{Scanning electron microscopy}

304 SEM micrographs of surface and cross-section of the control membranes, membranes with AQP-0, 305 AQP-1 are presented in Figure 2.

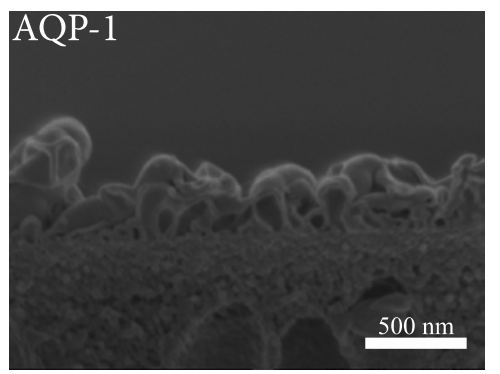

Figure 2. SEM micrographs of prepared polyamide membranes - Control, AQP-1 and AQP-0. A - top views of the 309 surfaces of polyamide active layer; $\mathrm{B}$ - top views of the surface of polyamide active layer; $\mathrm{C}$ - cross section of the membranes. 
310 The addition of polymersomes did not affect the thickness of the polyamide layer. For all membranes,

311 the thickness of the polyamide was comparable - ranging from 200 to $350 \mathrm{~nm}$. However, from the 312 cross-section micrographs it can be seen that the morphology of the control membrane is different 313 than for the AQP-0 and AQP-1 membranes. When polymersomes are introduced, there is a visible 314 increase in the number of hollow spaces within the bulk polyamide layer - both for AQP-0 and AQP315 1. The surface morphology of the control membrane was also different when compared to AQP-1 and 316 AQP-0, whereas AQP-1 and AQP-0 are comparable. As polymersomes are expected to take part in 317 the interfacial polymerization reaction through amino-terminated chains of A-PDMS, it is likely that 318 the resulting polyamide layer has a different appearance compared to the membrane without 319 polymersomes. Since AQP-0 and AQP-1 have the same characteristics and the only difference 320 between them is the reconstitution of AqpZ proteins for AQP-1, the same type of TFC layer 321 morphology is observed. The single polymersomes are not visible, as they become an integral part of 322 the polymer matrix when they are covered by it. Due to the size of the AqpZ protein tetramer, which 323 only spans a few nm [46], the morphology difference between AQP-0 and AQP-1 cannot be observed 324 on the SEM micrographs. 
327 The XPS analysis of the selective layer was made to determine the elemental composition of the 328 formed polyamide film. The concentrations of C, N, O, S and Si in the selective layer, obtained with 329 XPS core spectra, are listed in Table 2.

Table 2. X-ray photoelectron spectroscopy spectra results. Concentrations of $C, N, O, S$ and Si of the support membrane, 331 control membrane, and membranes loaded with AQP-0 and AQP-1.

\begin{tabular}{cccccc}
\hline Sample name & C concentration & N concentration & O concentration & S concentration & Si concentration \\
& $(\%)$ & $(\%)$ & (\%) & (\%) & - \\
\hline Support membrane & $77.6 \pm 0.6$ & $2.1 \pm 0.2$ & $18.1 \pm 0.5$ & - & $0.3 \pm 0.1$ \\
Control membrane & $74.3 \pm 0.7$ & $11.4 \pm 0.3$ & $14.0 \pm 0.5$ & - & $0.1 \pm 0.1$ \\
AQP-0 membrane & $74.6 \pm 0.7$ & $10.1 \pm 0.3$ & $15.2 \pm 0.6$ & - & $0.1 \pm 0.1$ \\
AQP-1 membrane & $73.7 \pm 0.7$ & $10.1 \pm 0.3$ & $16.2 \pm 0.8$ & & - \\
\hline
\end{tabular}

333 In comparison to the support, the concentration of $\mathrm{C}$ and $\mathrm{O}$ dropped for the control membrane and 334 AQP-0 and AQP-1 membranes, while the concentration of $\mathrm{N}$ increased due to the polyamide layer 335 formed on top of the membrane. Regarding the spectra for the polyamide membranes, there is no 336 longer a peak from S, indicating a full coverage of the support with a polyamide thin film for all 337 membrane samples. Concentrations of $\mathrm{N}$ decreased by $1.5 \%$, while concentration of $\mathrm{O}$ increased by 338 1-2 \% for both AQP-0 and AQP-1 membranes in comparison to the control. This indicates that the 339 elemental composition of polyamide formed when polymersomes are introduced differs form the 340 polyamide without polymersomes. We speculate that the elevated concentration of oxygen indicates 341 incorporation of PMOXA-PDMS-PMOXA and amino-PDMS via reaction with TMC. 342 Counterintuitively, the content of $\mathrm{Si}$ is the highest for the control membrane and drops for AQP-0 343 and AQP-1, where Si-containing polymers have been introduced. However, the content of Si is at the 
344 lower limit of detection, with a high standard deviation, which may be a result of sample cross 345 contamination, as all of the samples were stored together overnight prior testing.

The $\zeta$-potential measurements of polyamide membranes and support are presented in Table 3.

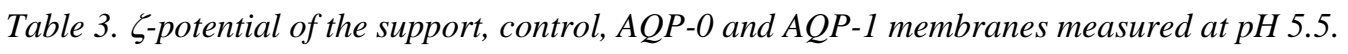

\begin{tabular}{ccc}
\hline Sample name & $\zeta$-potential $(\mathbf{m V})$ & Standard Deviation \\
\hline Support Membrane & -20.13 & \pm 1.63 \\
Control Membrane & -28.93 & \pm 0.34 \\
AQP-0 membrane & -36.05 & \pm 1.97 \\
AQP-1 membrane & -34.50 & \pm 0.77 \\
\hline
\end{tabular}

351 As expected, measured $\zeta$-potential for all of the polyamide coated membranes was about 9 - $16 \mathrm{mV}$ 352 more negative than $\zeta$-potential for the support membrane. Lower $\zeta$-potential of polyamide coated 353 membranes indicated a more negatively charged surface of the membrane and in fact again confirms 354 the successful coating of the polyamide layer on top of the membrane support. The polyamide coated 355 membranes had similar $\zeta$-potential, but for the AQP-0 and AQP-1 doped membranes, the $\zeta$-potential 356 was $5.57-7.12 \mathrm{mV}$ more negative than for the control membrane. Taking into account the accuracy 357 of the measurement method and standard deviations, we assume that this slight change has a minor 358 impact on the separation properties between control membrane and membranes doped with 359 polymersomes: AQP-0 and AQP-1. 
364 Water permeability and $\mathrm{NaCl}$ rejection of the control membranes, membranes doped with AQP-0 and 365 membranes doped with AQP-1 polymersomes are presented in Figure 3. For each type of RO 366 membrane, 9 coupons were tested.

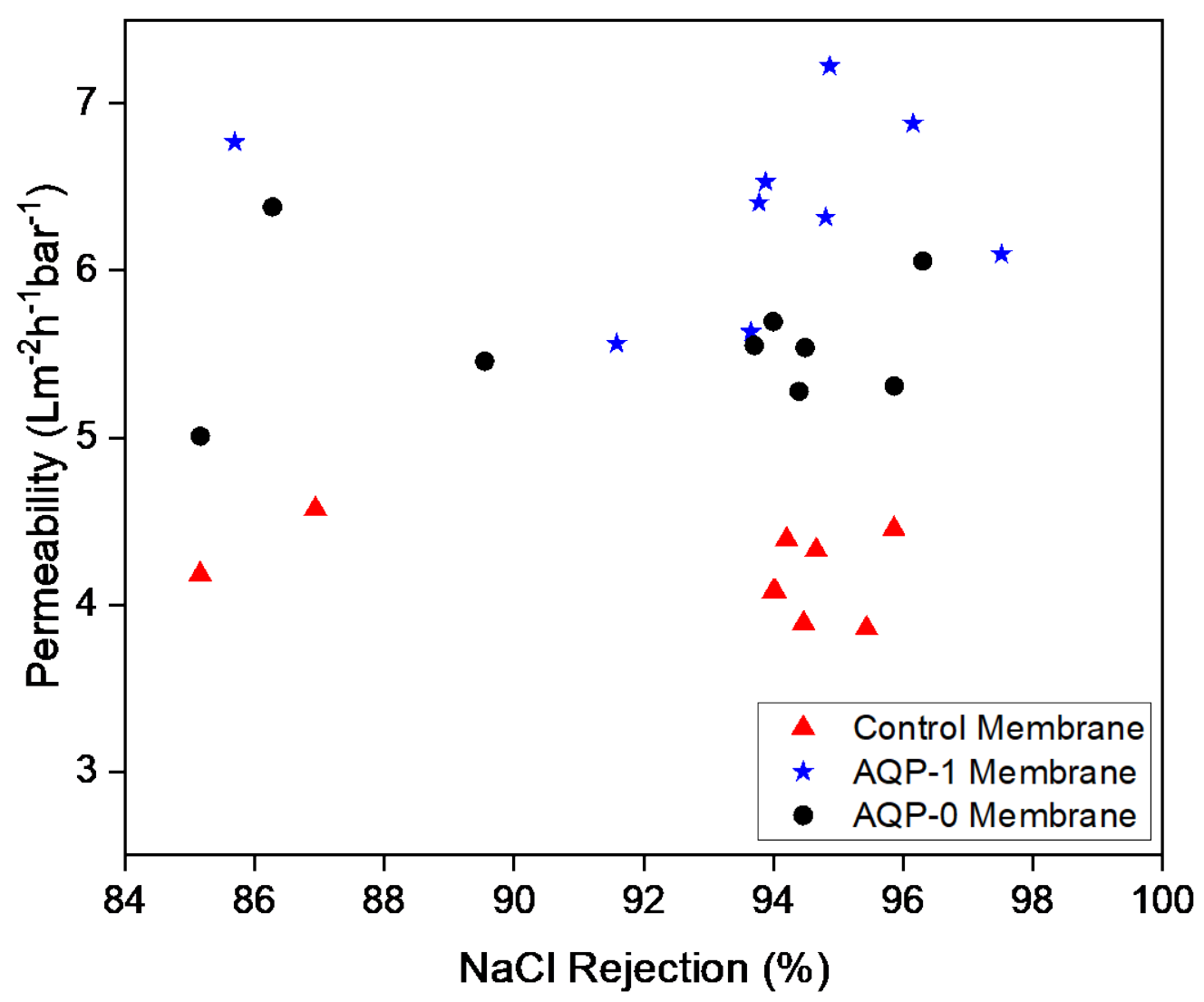

Figure 3. Water permeability and $\mathrm{NaCl}$ rejection of membrane samples without polymersomes, with $A Q P-0$ polymersomes and AQP-1 polymersomes. The membranes were tested at 5 bars with $500 \mathrm{ppm} \mathrm{NaCl}$ as feed solution, at $25^{\circ} \mathrm{C}$ and feed flow rate of $60 \mathrm{Lh}^{-1}$.

372 The control membranes, which are composed of a polyamide layer without polymersomes, resulted 373 in an average water permeability of $4.20 \pm 0.25 \mathrm{Lm}^{-2} \mathrm{~h}^{-1} \mathrm{bar}^{-1}$ and a $\mathrm{NaCl}$ rejection of $92.7 \pm 3.9 \%$.

374 The membranes with AQP-0 polymersomes exhibited increased water permeability in comparison to 375 the control membrane: $5.59 \pm 0.42 \mathrm{Lm}^{-2} \mathrm{~h}^{-1} \mathrm{bar}^{-1}$, while maintaining comparable rejection of $\mathrm{NaCl}$ : 
$92.2 \pm 4.1 \%$. The highest average water permeability was observed for the samples prepared with AQP-1, which was $6.38 \pm 0.55 \mathrm{Lm}^{-2} \mathrm{~h}^{-1} \mathrm{bar}^{-1}$ and $\mathrm{NaCl}$ rejection was also maintained at $93.5 \pm 3.4 \%$. Statistical analysis with One-Way ANOVA and the Tukey Test was made for each pair of membrane permeability datasets and confirmed that each set of prepared membranes is significantly different from the others (for all comparisons of the pairs, the p-value was always $<0.05$, with an overall ANOVA p-value of $4.34 \cdot 10^{-10}$ and an F-value of 60.33 with F-critical of 3.43) (Figure 4).

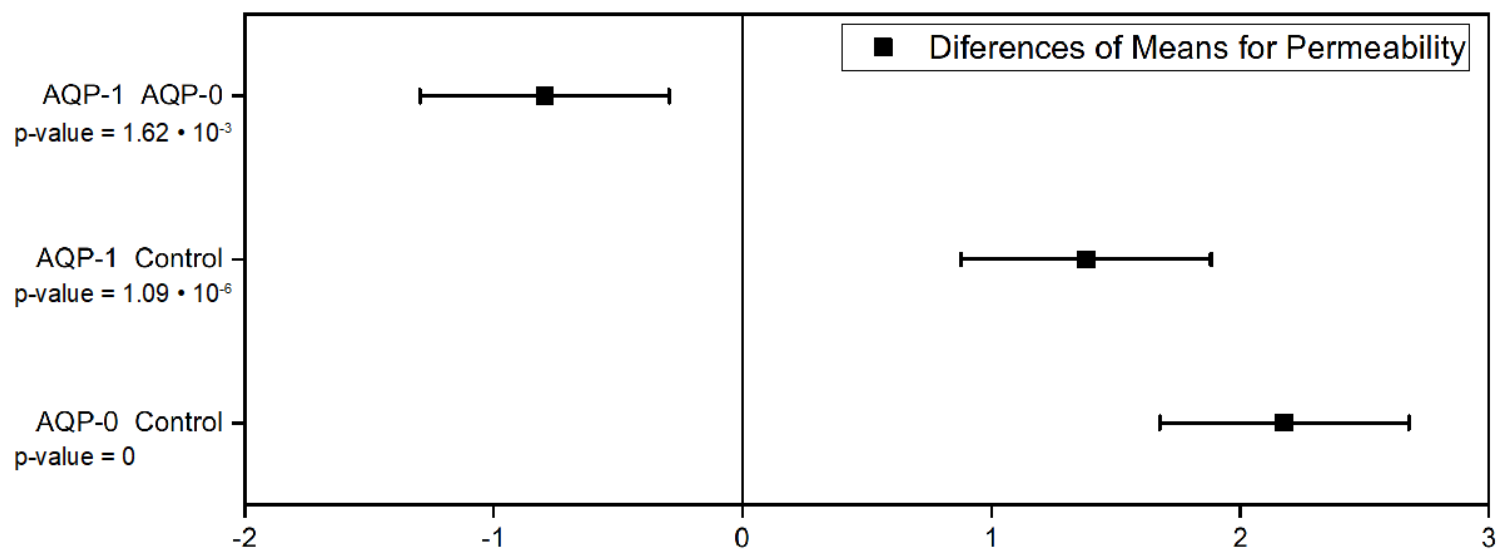

Figure 4. Tukey test means comparison plot for permeability of different membrane sets. If an interval does not contain 0 , the corresponding means of pairs are significantly different.

Compared to the membranes without polymersomes (control), addition of AQP-0 polymersomes increased water permeability by $33 \%$, while the $\mathrm{NaCl}$ rejection was maintained at the same level. Membranes prepared with AQP-1 polymersomes resulted in a further increase in performance, compared to the control, with an improved water permeability of $51 \%$ and comparable $\mathrm{NaCl}$ rejection. The permeability increase with AQP-1 compared to AQP-0 was $14 \%$. The increased water permeability after addition of AQP-0, clearly indicates that the polymersomes contribute to 391 facilitation of water transport through the TFC active layer, due to high water permeability through their triblock copolymer membrane wall, confirmed by the SFLS. Similarly, Qi et al. used PMOXAPDMS-PMOXA polymersomes to improve water permeability [39]. Additionally, the improved 
water permeability can be explained by the incorporation of the hollow nanostructures in the polyamide layer, corresponding to the case recently reported by Ma et al.; in their work, the nanobubbles formed during IP reactions were responsible for the facilitation of water permeability [47]. Here, the AQP-0 polymersomes may play a similar role. Furthermore, $\mathrm{NH}_{2}$ groups from aminomodified PDMS chains within polymersomes, may compete with MPD in interfacial polymerization reactions. The resulting membrane will be less densely cross-linked, as long PDMS chains will be introduced in the polyamide - the results obtained from XPS clearly indicate that the structure of the formed polyamide has changed (Table 2).

Finally, the use of AQP-1 can increase the water permeability even further than AQP-0. This indicates that AqpZ activity is maintained when AQP-1 are incorporated into the active layer matrix of the membrane. The additional increase in water permeability suggests that the water transport is facilitated through the AqpZ channels, which have been functionally reconstituted to the ABA copolymer membrane of the polymersomes. We speculate that the addition of the amino-modified PDMS during reconstitution of the AQP-0 and AQP-1 polymersomes and the incorporation of those polymer chains into the vesicles allowed for covalent bonding of the polymersomes to the polyamide matrix. As a result, rejection of the $\mathrm{NaCl}$ was maintained at the same level for all the tested membranes, even though water permeability increased significantly.

\section{Conclusions}

Highly permeable $\mathrm{NH}_{2}$-functionalized triblock PMOXA-PDMS-PMOXA copolymer polymersomes prepared by a bulk hydration method can functionally reconstitute AqpZ proteins. In this study, it has been shown that such polymersomes, which can reconstitute AqpZ water channel proteins can be successfully used for improving the permeability of reverse osmosis membranes without affecting the thickness nor the surface charge of the resulting polyamide layer. Changed elemental composition 
418 of the polyamide layer proves that the triblock copolymer is being incorporated into the polyamide.

419 Additionally, incorporation of the blank polymersomes improves water permeability, but an even 420 greater increase in permeability can be achieved with the introduction of Aquaporin Z proteins. The 421 approach for biomimetic membrane fabrication used in this study is based on industrially well-known 422 interfacial polymerization synthesis of polyamide and is therefore relatively easy to upscale to full423 size membrane production. Furthermore, since the bulk hydration self-assembly method for 424 preparation of polymersomes does not require multiple steps (such as film rehydration), upscaling of 425 the polymersome production process is also possible. The proposed approach offers great promise 426 for water treatment technology due to the combination of improved membrane performance coupled 427 with process scalability for large-scale industrial biomimetic membrane manufacturing.

\section{Acknowledgements}

430 The authors would like to thank Dr. Jörg Vogel for support and feedback during the research work 431 and writing this article, Scott Treven Myers for scientific feedback and proof reading and 432 Katrine Veis for language related feedback.

434 This work is co-founded by Aquaporin A/S and the Innovation Fund Denmark under the project 435 Development of Next Generation of Aquaporin Inside ${ }^{T M}$ membranes and EU Horizon 2020 project 436 Aquaporin-Inside ${ }^{\mathrm{TM}}$ Membranes for Brackish water Reverse Osmosis Application (AMBROSIA), 437 grant agreement ID 783848. 
443 [1] B.F. Milan, Clean water and sanitation for all: interactions with other sustainable development goals, Sustain. Water Resour. Manag. 3 (2017) 479-489. doi:10.1007/s40899017-0117-4.

[2] United Nations Environment: UN-WATER, The United Nations World Water Development Report 2018: Nature-Based Solutions for Water, UNESCO, Paris, France, 2018. www.unesco.org/open-access/.

[3] H.T. Madsen, N. Bajraktari, C. Hélix-Nielsen, B. Van der Bruggen, E.G. Søgaard, Use of biomimetic forward osmosis membrane for trace organics removal, J. Memb. Sci. 476 (2015) 469-474. doi:10.1016/j.memsci.2014.11.055.

[4] M. Shannon, P.W. Bohn, M. Elimelech, J.G. Georgiadis, B.J. Mariñas, A.M. Mayes, Science 453

and technology for water purification in the coming decades, Nature. 452 (2008) 301-310. doi:10.1038/nature06599.

[5] T. Hey, N. Bajraktari, J. Vogel, C. Hélix Nielsen, J. la Cour Jansen, K. Jönsson, The effects of physicochemical wastewater treatment operations on forward osmosis, Environ. Technol. 0 (2016) 1-13. doi:10.1080/09593330.2016.1246616. 
doi:10.1016/j.memsci.2013.01.031.

[9] H. Elfil, A. Hamed, A. Hannachi, Technical evaluation of a small-scale reverse osmosis desalination unit for domestic water, Desalination. 203 (2007) 319-326. doi:10.1016/j.desal.2006.03.530.

[10] D. Li, Y. Yan, H. Wang, Recent advances in polymer and polymer composite membranes for reverse and forward osmosis processes, Prog. Polym. Sci. 61 (2016) 104-155. doi:10.1016/j.progpolymsci.2016.03.003.

[11] C.Y. Tang, Y. Zhao, R. Wang, C. Hélix-Nielsen, A.G. Fane, Desalination by biomimetic aquaporin membranes: Review of status and prospects, Desalination. 308 (2013) 34-40. doi:10.1016/j.desal.2012.07.007.

[12] C. Tang, Z. Wang, I. Petrinic, A.G. Fane, C. Hélix-Nielsen, Biomimetic aquaporin membranes coming of age, Desalination. 368 (2014) 89-105. doi:10.1016/j.desal.2015.04.026.

[13] X. Li, S. Chou, R. Wang, L. Shi, W. Fang, G. Chaitra, C.Y. Tang, J. Torres, X. Hu, A.G. Fane, Nature gives the best solution for desalination: Aquaporin-based hollow fiber composite membrane with superior performance, J. Memb. Sci. 494 (2015) 68-77. doi:10.1016/j.memsci.2015.07.040.

[14] P.A. Pedersen, F.B. Bjørkskov, S. Alvisse, C. Hélix-Nielsen, From channel proteins to industrial biomimetic membrane technology, Faraday Discuss. 209 (2018) 287-301. doi:10.1039/c8fd00061a.

[15] C. Helix-Nielsen, Biomimetic Membranes for Sensor and Separation Applications, 2015. doi:10.1017/CBO9781107415324.004.

[16] C.G. Palivan, R. Goers, A. Najer, X. Zhang, A. Car, W. Meier, Bioinspired polymer vesicles and membranes for biological and medical applications, Chem. Soc. Rev. 45 (2016) 377- 
411. doi:10.1039/C5CS00569H.

[17] M.P. Grzelakowski, Novel Polymers and Process for Making Membranes, WO 2015/144725 A1, 2015.

[18] F. Itel, A. Najer, C.G. Palivan, W. Meier, Dynamics of Membrane Proteins within Synthetic Polymer Membranes with Large Hydrophobic Mismatch, (2015). doi:10.1021/acs.nanolett.5b00699.

[19] M. Kumar, M. Grzelakowski, J. Zilles, M. Clark, W. Meier, Highly permeable polymeric membranes based on the incorporation of the functional water channel protein Aquaporin Z, Proc. Natl. Acad. Sci. U. S. A. 104 (2007) 20719-24. doi:10.1073/pnas.0708762104.

[20] H. Wang, T.S. Chung, Y.W. Tong, K. Jeyaseelan, A. Armugam, Z. Chen, M. Hong, W. Meier, Highly permeable and selective pore-spanning biomimetic membrane embedded with Aquaporin Z, Small. 8 (2012) 1185-1190. doi:10.1002/smll.201102120.

[21] M. Grzelakowski, M.F. Cherenet, Y. xiao Shen, M. Kumar, A framework for accurate evaluation of the promise of aquaporin based biomimetic membranes, J. Memb. Sci. 479 (2015) 223-231. doi:10.1016/j.memsci.2015.01.023.

[22] M.P. Grzelakowski, Novel Polymers and Process for Making Membranes, WO 2015/144725, 2018.

[23] D. Wu, M. Spulber, F. Itel, M. Chami, T. Pfohl, C.G. Palivan, W. Meier, Effect of molecular parameters on the architecture and membrane properties of $3 \mathrm{D}$ assemblies of amphiphilic copolymers, Macromolecules. 47 (2014) 5060-5069. doi:10.1021/ma500511r.

[24] N. Muhammad, T. Dworeck, M. Fioroni, U. Schwaneberg, Engineering of the E . coli Outer Membrane Protein FhuA to overcome the Hydrophobic Mismatch in Thick Polymeric Membranes, Journal of Nanobiotechnology 9:8 (2011) 1-9. 
[25] M. Spulber, D. Tvermoes, R. Górecki, F. Haugsted, Vesicle Incorporating Transmembrane Protein, WO 2019/081371 A1, 2019.

[26] Y. Zhao, C. Qiu, X. Li, A. Vararattanavech, W. Shen, J. Torres, C. Hélix-Nielsen, R. Wang, X. Hu, A.G. Fane, C.Y. Tang, Synthesis of robust and high-performance aquaporin-based biomimetic membranes by interfacial polymerization-membrane preparation and $\mathrm{RO}$ performance characterization, J. Memb. Sci. 423-424 (2012) 422-428. doi:10.1016/j.memsci.2012.08.039.

[27] R. Sengur-Tasdemir, B. Sayinli, G.M. Urper, H.E. Tutuncu, N. Gul-Karaguler, E. AtesGenceli, V. V. Tarabara, I. Koyuncu, Hollow fiber nanofiltration membranes with integrated aquaporin Z, New J. Chem. 42 (2018) 17769-17778. doi:10.1039/C8NJ04367A.

[28] X. Li, C.H. Loh, R. Wang, W. Widjajanti, J. Torres, Fabrication of a robust highperformance FO membrane by optimizing substrate structure and incorporating aquaporin into selective layer, J. Memb. Sci. 525 (2016) 257-268. doi:10.1016/j.memsci.2016.10.051.

[29] D.E. Discher, A. Eisenberg, Polymer Vesicles, Science 297 (2002) 967-973

[30] P.H.H. Duong, T.S. Chung, K. Jeyaseelan, A. Armugam, Z. Chen, J. Yang, M. Hong, Planar biomimetic aquaporin-incorporated triblock copolymer membranes on porous alumina supports for nanofiltration, J. Memb. Sci. 409-410 (2012) 34-43. doi:10.1016/j.memsci.2012.03.004.

[31] P.S. Zhong, T.S. Chung, K. Jeyaseelan, A. Armugam, Aquaporin-embedded biomimetic membranes for nanofiltration, J. Memb. Sci. 407-408 (2012) 27-33. doi:10.1016/j.memsci.2012.03.033.

[32] L. Xia, M.F. Andersen, C.H. Nielsen, J.R. McCutcheon, Novel Commercial Aquaporin Flatsheet Membrane for Forward Osmosis, Ind. Eng. Chem. Res. (2017) 11919-11925. 
doi:10.1021/acs.iecr.7b02368.

[33] W. Xie, F. He, B. Wang, T.-S. Chung, K. Jeyaseelan, A. Armugam, Y.W. Tong, An aquaporin-based vesicle-embedded polymeric membrane for low energy water filtration, J. Mater. Chem. A. 1 (2013) 7592. doi:10.1039/c3ta10731k.

[34] D. Li, Y. Yan, H. Wang, Recent advances in polymer and polymer composite membranes for reverse and forward osmosis processes, Prog. Polym. Sci. (2016). doi:10.1016/j.progpolymsci.2016.03.003.

[35] A. Wagner, K. Vorauer-Uhl, Liposome Technology for Industrial Purposes, J. Drug Deliv. 2011 (2011) 1-9. doi:10.1155/2011/591325.

[36] X. Sui, P. Kujala, G.J. Janssen, E. De Jong, I.S. Zuhorn, J.C.M. Van Hest, Robust formation of biodegradable polymersomes by direct hydration, Polym. Chem. 6 (2015) 691-696. doi:10.1039/c4py01288g.

[37] M. Spulber, K. Gerstandt, Diblock Copolymer Vesicles and Separation Membranes Comprising Aquaporin Water Channels and Methods of Making and Using Them, WO 2018/141985 A1, 2018.

[38] A. Horner, P. Pohl, Single-file transport of water through membrane channels, Faraday Discuss. 209 (2018) 9-33. doi:10.1039/c8fd00122g.

[39] S. Qi, W. Fang, W. Siti, W. Widjajanti, X. Hu, R. Wang, Polymersomes-based highperformance reverse osmosis membrane for desalination, J. Memb. Sci. 555 (2018) 177184. doi:10.1016/j.memsci.2018.03.052.

[40] F.B. Bjørkskov, S.L. Krabbe, C.N. Nurup, J.W. Missel, M. Spulber, J. Bomholt, K. Molbaek, C. Helix-Nielsen, K. Gotfryd, P. Gourdon, P.A. Pedersen, Purification and functional comparison of nine human Aquaporins produced in Saccharomyces cerevisiae for the purpose of biophysical characterization, Sci. Rep. 7 (2017). 
563 [41] H.X. Gan, H. Zhou, Q. Lin, Y.W. Tong, Quantification of Aquaporin-Z reconstituted into 564 vesicles for biomimetic membrane fabrication, Sci. Rep. 7 (2017) 1-13. doi:10.1038/s41598-017-11723-X.

566 [42] M. Chau, H. Chu, W. Light, Dry High Flux Semipermeable Membranes, WO 91/08828, 1991.

568 [43] T. Tadros, Colloid and interface aspects of pharmaceutical science, Elsevier B.V., 2014. doi:10.1016/B978-0-444-62614-1.00002-8.

[44] V. Pata, F. Ahmed, D.E. Discher, N. Dan, Membrane Solubilization by Detergent : Resistance Conferred by Thickness, Langmuir. 20 (2004) 3888-3893. doi:10.1021/la035734e.

[45] S. Pispas, Vesicular structures in mixed block copolymer / surfactant solutions, Soft Matter. 7 (2011) 8697-8701. doi:10.1039/c1sm05584d.

575 [46] A.S. Verkman, A.K. Mitra, Structure and function of aquaporin water channels, Am.. J. Physiol. Ren. Physiol. 278 (2000) F13-F28. doi:10.1002/mus.20766.

577 [47] X.-H. Ma, Z. Yao, Z. Yang, H. Guo, Z. Xu, C.Y. Tang, M. Elimelech, Nanofoaming of 578 Polyamide Desalination Membranes To Tune Permeability and Selectivity, Environ. Sci. \& Technol. Lett. 5 (2018) 123-130. doi:10.1021/acs.estlett.8b00016. 